Clemson University

TigerPrints

2017

Elementary science teachers' integration of engineering design into science instruction: results from a randomised controlled trial

Jennifer L. Maeng

Brooke A. Whitworth

Amanda L. Gonczi

Shannon L. Navy

Lindsay B. Wheeler

Follow this and additional works at: https://tigerprints.clemson.edu/teach_learn_pub

Part of the Science and Mathematics Education Commons 


\section{IJ International Journal of Science Education}

\section{Elementary science teachers' integration of engineering design into science instruction: results from a randomised controlled trial}

Jennifer L. Maeng , Brooke A. Whitworth, Amanda L. Gonczi, Shannon L. Navy \& Lindsay B. Wheeler

To cite this article: Jennifer L. Maeng , Brooke A. Whitworth, Amanda L. Gonczi, Shannon L. Navy \& Lindsay B. Wheeler (2017): Elementary science teachers' integration of engineering design into science instruction: results from a randomised controlled trial, International Journal of Science Education, DOI: 10.1080/09500693.2017.1340688

To link to this article: http://dx.doi.org/10.1080/09500693.2017.1340688

Published online: 28 Jun 2017.

Submit your article to this journal

Џ Article views: 13

View related articles

View Crossmark data $\asymp$ 


\title{
Elementary science teachers' integration of engineering design into science instruction: results from a randomised controlled trial
}

\author{
Jennifer L. Maeng (iD ${ }^{a}$, Brooke A. Whitworth ${ }^{\text {bt }}$, Amanda L. Gonczic, Shannon L. Navy ${ }^{d}$ \\ and Lindsay B. Wheeler ${ }^{a}$ \\ ${ }^{a}$ Curry School of Education, University of Virginia, Charlottesville, VA, USA; ${ }^{b}$ Center for Science Teaching and \\ Learning, Northern Arizona University, Flagstaff, AZ, USA; 'Greater Lakes Research Center, Michigan Technical \\ University, Houghton, MI, USA; ${ }^{\text {DDeparatment }}$ of Education, Valparaiso University, Valparasio, IN, USA
}

\begin{abstract}
This randomised controlled trial used a mixed-methods approach to investigate the frequency and how elementary teachers integrated engineering design (ED) principles into their science instruction following professional development (PD). The ED components of the PD were aligned with Cunningham and Carlsen's [(2014). Teaching engineering practices. Journal of Science Teacher Education, 25, 197-210] guidelines for ED PD and promoted inclusion of ED within science teaching. The treatment group included 219 teachers from 83 schools. Participants in the control group included 145 teachers from 60 schools in a mid-Atlantic state. Data sources, including lesson overviews and videotaped classroom observations, were analysed quantitatively to determine the frequency of ED integration and qualitatively to describe how teachers incorporated ED into instruction after attending the PD. Results indicated more participants who attended the PD (55\%) incorporated ED into instruction compared with the control participants $(24 \%), x^{2}(1, n=401)=33.225, \quad p<.001, \quad r_{\phi}=0.308$. Treatment and control teachers taught similar science content ( $p^{\prime} s$ $>.05$ ) through ED lessons. In ED lessons, students typically conducted research and created and tested initial designs. The results suggest the PD supported teachers in implementing ED into their science instruction and support the efficacy of using Cunningham and Carlsen's (2014) guidelines to inform ED PD design.
\end{abstract}

\section{ARTICLE HISTORY}

Received 27 February 2017

Accepted 6 June 2017

\section{KEYWORDS}

Elementary; randomised control trial; engineering design

Children create forts in their bedrooms and in the woods, design buildings and bridges from blocks, and draw and envision things that do not exist. Recent reforms in science education leverage these natural instincts children have to design, create, and solve problems by promoting the integration of engineering design (ED) into science instruction (e.g. Cunningham \& Carlsen, 2014; Katehi, Pearson, \& Feder, 2009; National Research Council [NRC], 2012). While engineering is distinct from science, both fields rely on scientific investigative skills to answer questions and solve problems (Dym, Agogino, Eris, Frey, \& Leifer, 2005; Katehi et al., 2009). The Framework for K-12 Science Education 
(NRC, 2012) emphasises helping K-12 students develop a deeper understanding of the engineering process through eight practices that can be embedded into science instruction: defining problems, developing and using models, planning and carrying out investigations, analysing and interpreting data, using mathematics and computational thinking, designing solutions, engaging in argument from evidence, and obtaining, evaluating, and communicating information. The Next Generation Science Standards (NGSS) recognises $\mathrm{ED}$ as an iterative, cyclic process; students may engage in one or more of these practices multiple times to solve a single problem.

With this recent emphasis in science education reforms on integrating ED into science education (e.g. NRC, 2012), it has become increasingly important to investigate how we teach and integrate engineering into K-12 education (Katehi et al., 2009). This study assessed the efficacy of ED professional development (PD) through a randomised control trial (RCT) research design. Specifically, we investigated the frequency of ED integration, science content addressed in ED tasks, and the components of the ED process elementary (grades 4-6) teachers incorporated into their science instruction following ED PD.

\section{ED in $\mathrm{K}-12$ education}

Incorporating engineering into the curriculum has the potential to increase student interest in and awareness of STEM careers, increase student STEM literacy, and make math and science relevant to students (Apedoe, Reynolds, Ellefson, \& Schunn, 2008; Katehi et al., 2009). Including ED in instruction increases student motivation (Barnett, 2005; Blumenfeld, Kempler, Krajcik, \& Blumenfeld, 2006) by enhancing students' sense of agency and encouraging students to take responsibility for their own learning (Fortus, Krajcik, Dershimer, Marx, \& Mamlok-Naaman, 2005). Furthermore, engineering projects can help students develop 21st Century Skills including critical thinking, communication, collaboration, and creativity (Partnership for 21st Century Skills, 2010). The iterative nature of the ED process in which students design, build, test, analyse, repeat, and improve allows them to repeatedly confront and address their preconceptions and have multiple opportunities to solidify their conceptual understandings (Hmelo, Holton, \& Kolodner, 2000; Klahr, Triona, \& Williams, 2007). Finally, engaging students in ED allows them to see that failure can provide opportunities to learn (Fortus et al., 2005; Kolodner, 2006). This is an important lesson and one that is not often taught or paid attention to in classrooms (Cunningham \& Carlsen, 2014). Given the many potential benefits of incorporating ED into instruction, it is important to consider how teachers enact ED tasks into science instruction.

\section{ED in science classrooms}

Science instruction couched within ED tasks is one way to facilitate development of students' scientific literacy and problem solving (Katehi et al., 2009). Embedding ED tasks into science instruction has the potential to make science relevant to students (Kolodner, Camp, Crismond, Fasse, \& Gracy, 2003) and helps students identify the importance of science in engineering (Kanter, 2010). It may also help to reduce the cognitive load for students as they utilise complex scientific concepts in the creation of concrete, physical models (Levy, 2013). 
A variety of learning objectives can be met by including ED tasks in science instruction. For example, a well-designed engineering task may result in new understandings of the science concepts under study (Kanter, 2010; Krajcik, McNeill, \& Reiser, 2008). In other cases, the goal may be to understand ED and apply science concepts to solve a problem rather than learn new science content through the task (Ainley, Pratt, \& Hansen, 2006). In these cases, researchers acknowledge that important science content may be left out when taught through ED (Cunningham \& Carlsen, 2014). However, in all cases, a welldesigned engineering task should seize students' attention and support students in solving an authentic real-world problem in ways similar to a practicing engineer. However, understanding how teachers are currently implementing ED in classrooms is understudied and is important in informing the design of PD to support teachers in ED instruction.

\section{Models of ED}

In their 2009 report Engineering in K-12 Education, the National Academy of Engineering and the National Research Council broadly define ED tasks as meeting three criteria:

(1) having a problem to solve (e.g. design a safe roller coaster, filter water for drinking, build a circuit to provide more light)

(2) students have options in design or construction (i.e. they are not told how to do it)

(3) there are constraints (e.g. design limitations) and specifications (design requirements) (Katehi et al., 2009).

According to this description of ED, students do not need to build a prototype (i.e. the design can be a written plan to solve a problem), nor is iterative design required. This conceptualisation of ED integration has supported curriculum interventions and learning gains in various studies (e.g. Apedoe et al., 2008; Chiu \& Linn, 2011).

The PD that served as the context for the present investigation assimilated the steps of several existing ED models (e.g. International Technology Education Association [ITEA], 2000; Katehi et al., 2009) and ultimately described the ED process as four linked and cyclic phases that include those criteria in Katehi et al. (2009):

(1) Identification of the problem (e.g. context, need, and specifications),

(2) Generation of design solutions (e.g. brainstorm, research, share ideas, and select),

(3) Create and improve models (complete detailed design, construct model, test and evaluate, improve model), and

(4) Communicate findings (Figure 1).

In addition to meeting the Katehi et al. (2009) criteria for ED, this model also includes explicit mention of problem definition, developing and using models, conducting investigations, testing, using mathematics and computational thinking, designing solutions, and communicating information, which are engineering practices highlighted in the Framework (2012). Finally, it provides a simplified yet accurate view of ED accessible to elementary teachers. 


\section{ENCINEERINE DESICN PRDCESS}

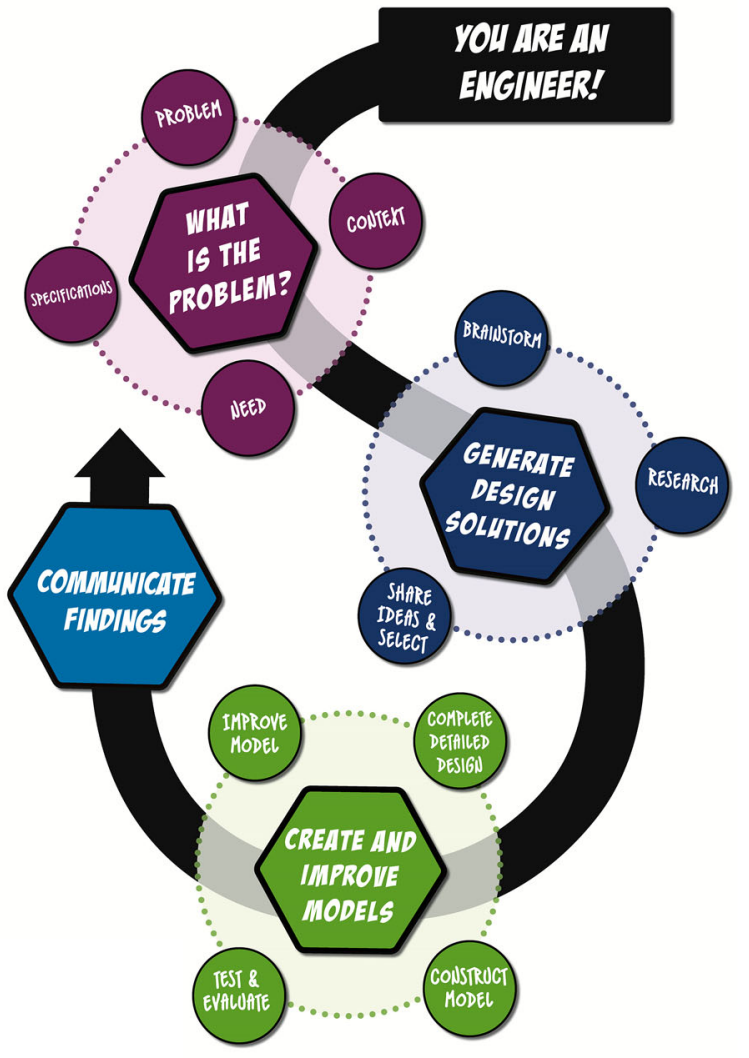

Figure 1. ED process taught in the PD.

\section{Elementary engineering curricula}

Many curricula currently exist that have the potential to support teachers in including engineering into science instruction (Brophy, Klein, Portsmore, \& Rogers, 2008; Katehi et al., 2009). Katehi et al. (2009) indicate that most elementary engineering curricula (e.g. A World in Motion, City Technology, Engineering is Elementary [EiE], Invention, Innovation and Inquiry $\left[\mathrm{I}^{3}\right]$ ) address physical science concepts related to 'materials, mechanisms, electricity, energy, and structures' and the concepts of 'force, work, motion, torque ... which are presented in the form of ... explanations ... then reinforced in laboratory activities' that involve scientific investigations (p. 80). In addition to physical science concepts, the EiE and $\mathrm{I}^{3}$ also include some environmental and life science concepts (e.g. organisms, plants, water). EiE also leverages elementary teachers' strengths by incorporating a literacy component into each unit. However, neither City Technology, EiE, nor $\mathrm{I}^{3}$ purports to target science content directly (Katehi et al., 2009). With these curricula, teachers are provided the curricula, ideally given instruction on how to implement it, and then expected to implement it as designed.

Studies of implementation of such prepared curricula suggest they have the potential to be effective in supporting teachers' integration of engineering into elementary science 
instruction and to achieve positive student outcomes when teachers implement them as intended (e.g. Brophy et al., 2008; Cunningham, 2009; Fortus et al., 2005). However, several challenges to ideal implementation exist. First, it is possible that science content not addressed in the curriculum will be left out or that key engineering concepts will not be included. For example, one criticism of the EiE curriculum is that 'treatment of concepts like constraints, modeling, and systems are a little irregular ...' (Katehi et al., 2009, p. C-96). Second, the cost (e.g. purchasing kits, books, and consumable materials) of packaged curricula is a concern. Third, the quality and access to support and PD available for teachers influence teachers' capacity to implement the curriculum with fidelity (Katehi et al., 2009). Given the constraints of prepared curricula, the current study sought to provide teachers with $\mathrm{PD}$ on ED and provide them with tools to support incorporating ED into the specific content area and grade level they taught.

\section{Science teacher PD}

A synthesis of the research on the characteristics of PD that support changes in science teachers' instructional practices suggests that it needs to be sustained and ongoing (e.g. Johnson, Kahle, \& Fargo, 2007; Supovitz, Mayer, \& Kahle, 2000), be focused on teachers' understanding of content and teaching methods through active learning (Desimone, 2009; Loucks-Horsley \& Matsumoto, 1999), and have coherence with previous and future PD activities and with teacher goals (Birman, Desimone, Porter, \& Garet, 2000). Research suggests expert coaching is one way to support teachers' practicing new instructional approaches in a sustained and coherent manner (e.g. Grierson \& Woloshyn, 2013; Loucks-Horsley, Stiles, Mundry, Love, \& Hewson, 2010; Luft et al., 2011). Finally, collective participation of several teachers from the same grade or school encourages group discussions that have the potential to enhance teacher learning (Birman et al., 2000; Borko, 2004; Loucks-Horsley \& Matsumoto, 1999).

The PD that served as the context of the present investigation was guided by these key components of effective PD with a goal of increasing student achievement in science (Desimone, 2009; Loucks-Horsley et al., 2010). Specifically, the PD promoted hands-on, inquiry-based science within problem-based learning (PBL) unit contexts. Participants also engaged in modules around integrating ED, literacy strategies, technology, and explicit nature of science (NOS) into science instruction. What participants learned and integrated into their classroom instruction as a result of the ED module was the focus of the present investigation.

\section{ED PD for teachers}

In 2003 the National Science Board recommended emphasising PD for K-12 science teachers to support their inclusion of engineering into instruction. Based on review of the research of PD related to implementing ED curricula and their experience planning and leading PD to support teachers' inclusion of engineering into instruction, Cunningham and Carlsen (2014) recommend five principles for designing engineering PD for teachers. First, teachers need to have opportunities to engage in engineering practices through hands-on, student-centred activities that model the design cycle. Second, facilitators should model pedagogy that supports engineering practices during PD. Cunningham 
and Carlsen (2014) specifically identify the importance of modelling the role of teacher-asfacilitator and providing teachers with strategies for questioning, group work, and communication. Third, teachers should have experiences as both learners and teachers and PD facilitators should be explicit with teachers about what 'hat' they wear during different parts of the PD. Teachers also need help in developing their understanding of engineering, technology, and the ED process and how these interact with science through explicit discussions and activities. Finally, teachers need to understand that engineering is a social practice and collaborative in nature.

Despite positive results seen from implementing these principles in ED PD for teachers, Cunningham and Carlsen (2014) caution that it can take three to six years before teachers truly feel comfortable implementing ED in their classrooms. These guiding principles of ED PD were well-aligned with the PD that served as the context of the investigation. One contribution of the present study is to provide rigorous support for Cunningham and Carlsen's (2014) principles for ED PD in the form of an RCT.

\section{Purpose}

The potential constraints of prepared curricula in terms of cost, teacher $\mathrm{PD}$, and alignment across content areas (e.g. few address life science content in tasks) and the dearth of research on $\mathrm{PD}$ that best supports elementary teachers in developing and integrating ED tasks into science instruction provide a substantive need for the present study. The purpose of this study was to explore the extent to and ways in which elementary (grades 4-6) teachers incorporated ED into their science instruction following a PD experience in which the ED component was aligned with the guiding principles developed by Cunningham and Carlsen (2014). The study also aimed to identify the content being taught through ED (e.g. life science, physics, chemistry, earth/space/environmental science) and the components of the ED process (e.g. problem identification, generate design solutions, create and improve models, communicate findings) implemented during the engineering lesson. The following research questions guided the investigation:

(1) To what extent did teachers participating in the PD integrate ED into instruction and how did this compare to integration of ED by teachers who did not participate in the $\mathrm{PD}$ ?

(2) How did teachers implement ED into their science instruction following participation in the PD?

(a) What content did they teach through ED lessons?

(b) What components of ED did they implement?

\section{Methods}

A cluster RCT design evaluated treatment participants' ED practices compared to a control group who did not participate in the PD. A convergent parallel mixed-methods approach in which the quantitative data (i.e. the extent of ED integration by treatment and control teachers) and qualitative data (classroom observations) were collected simultaneously via observation forms and videotaped classroom observations, analysed 
separately, and interpreted collectively to develop a complete understanding of how elementary teachers incorporate ED into science instruction (Creswell \& Plano Clark, 2011).

\section{Participants/context}

For each of three cohorts, fourth through sixth grade teachers from a mid-Atlantic state applied and were randomised at the school level into treatment or control conditions via straight random assignment. Randomisation at the school level reduced the potential for contamination across conditions and encouraged collective participation among teachers. Participants in the treatment condition were 219 teachers (26 male and 188 female) from 83 schools ranging in experience from 0 to 41 years with an average of 12.1years $(S D=8.4)$. Participants in the control condition included 145 teachers $(20$ male and 113 female) from 60 schools who ranged in experience from 0 to 39 years with an average of 11.9 years $(\mathrm{SD}=8.6)$. Demographic data (Table 1) were self-report and all participants were assigned a participant ID.

Treatment teachers attended a 4-week summer institute (152 contact hours) with academic year follow-up and coaching at 1 of 4 universities. Control teachers received no PD during their first year in the study and then were able to participate in the PD during their second year in the study. Thus, in this study data from control teachers were from the year prior to their participation in the PD.

University science educators, scientists, engineers, and science and mathematics specialists co-planned and facilitated the summer institute. As described above, the PD promoted inquiry-based science within a PBL context and supported participants in learning about integrating ED, literacy strategies, technology and explicit NOS instruction into science instruction through short modules. See Mannarino, Logerwell, Reid, and Edmondson (2012) for a complete description of the PD intervention. Following the summer institute, teachers in the treatment condition also received expert coaching support during the academic year and participated in four days of follow-up PD. The PD was implemented consistently across sites and cohorts (Bell, Konold, Maeng, \& Heinecke, 2014); therefore treatment teachers were combined across sites and cohorts for the present investigation.

\section{ED instruction}

During the summer institute, all treatment teachers learned about ED during a four-hour module. The ED module afforded the participants opportunities to design a solution to an open-ended problem. Physical manipulatives were provided to inform the solution design

Table 1. Participant demographic data.

\begin{tabular}{|c|c|c|c|c|c|c|c|}
\hline \multirow[b]{2}{*}{ Condition } & \multicolumn{2}{|c|}{ Gender } & \multicolumn{5}{|c|}{ Ethnicity } \\
\hline & Female & Male & Caucasian & $\begin{array}{l}\text { African- } \\
\text { American }\end{array}$ & Hispanic & Asian & $\begin{array}{c}\text { Native } \\
\text { American }\end{array}$ \\
\hline $\begin{array}{l}\text { Treatment }(n= \\
219)\end{array}$ & $188(85.5 \%)$ & 26 (11.9\%) & $158(72.2 \%)$ & $49(22.4 \%)$ & $3(1.4 \%)$ & $2(.9 \%)$ & $2(.9 \%)$ \\
\hline Control $(n=145)$ & $113(77.9 \%)$ & $20(13.8 \%)$ & 109 (75.2\%) & $20(13.8 \%)$ & $3(2.1 \%)$ & $1(.7 \%)$ & $0(0 \%)$ \\
\hline
\end{tabular}

Note: Not all teachers reported gender and ethnicity information. Five teachers in the treatment condition and 12 teachers in the control condition did not report demographic information. Percentages reported are for respondents to each demographic question. 
to support the hands-on emphasis within the broader PD programme. The module began by eliciting teachers' ideas about ED. Then, the teachers and facilitators discussed differences between science and engineering to support accurate nature of engineering conceptions (Dare, Ellis, \& Roehrig, 2014). Teachers were then presented with a design challenge.

This challenge utilised the ED process presented in Figure 1; however, the context of the task varied across cohorts based on the overarching content emphasis of the summer PD. For example, one cohort was tasked with building a 'desalination facility' to provide fresh water for drinking, cooking, etc. They had to produce a minimum of $20 \mathrm{~mL}$ of fresh water in 30 minutes using provided materials (e.g. tissue paper, coffee filters, funnels, beakers, cups, heat sources, etc.). Another cohort was tasked with constructing a non-fossil-fuelbased car with given materials (e.g. car base, cardboard, dowels, glue, binder clips, etc.) that could move a load undamaged a specified distance within five minutes. Regardless of the challenge topic, teachers were provided with the context and need, specifications, materials they could use, and evaluation criteria.

Across sites and cohorts, the teachers worked in groups to generate designs, test their designs, iterate on their initial designs, and retest their designs. Then, they communicated their design and its success relative to the specifications. The evaluation criteria for each challenge included a design sketch, accurate data, an explanation of why the design works, and whether the specifications were met.

After engaging in the ED challenge, facilitators led debrief sessions on teachers' experiences participating in a design challenge, reviewed the ED process, and shared a number of resources with teachers to facilitate their integration of ED into science instruction. Following the ED module, teachers had the opportunity to apply what they learned about ED by incorporating it into the PBL unit they designed as part of the broader summer institute for integration into their classroom science instruction. Thus, the total time treatment teachers spent during the summer institute involved in ED tasks ranged from 8 to 24 hours. Table 2 shows the alignment between the ED PD module components and Cunningham and Carlsen's (2014) guiding principles.

\section{Data collection and analysis}

Data for all treatment and control teachers consisted of classroom observation forms and videotaped classroom observations as described below. Classroom observations were conducted four times at regular intervals throughout the academic year, within the same three-week interval for all teachers.

\section{Observation forms}

For each of four observation windows, each teacher documented contextual information (i.e. objectives and activity descriptions) for the three science lessons prior to and following the observed lesson on observation forms. Observation forms were analysed for the presence (1) or absence (0) of ED in each of the up to seven lessons described. ED was defined as being present if: (1) there was a problem to solve, (2) students had options in design or construction, and (3) there are constraints and specifications. Three coders initially coded a subset of the data (20\%) independently using these criteria. Discrepancies in coding were discussed and resulted in $100 \%$ agreement among coders. The remainder of 
Table 2. Components of ED module and alignment with effective ED PD.

\begin{tabular}{|c|c|}
\hline Summer institute ED PD module component & Cunningham and Carlsen (2014) principle \\
\hline $\begin{array}{l}\text { Teachers engage in model lessons (e.g. desalination facility, } \\
\text { non-fossil-fuel-based car) and go through entirety of } \\
\text { design process }\end{array}$ & Engage Teachers in Engineering Practices \\
\hline $\begin{array}{l}\text { Model ED lessons include opportunities for collaboration, } \\
\text { PD facilitators acted as teachers and modelled facilitation, } \\
\text { questioning strategies, sharing designs }\end{array}$ & Model Pedagogies that Support Engineering Practices \\
\hline $\begin{array}{l}\text { Model ED lessons, debrief discussions following model } \\
\text { lessons, support to design ED lessons to include in PBL } \\
\text { units (e.g. resources) }\end{array}$ & Give Teachers Experiences as Teachers and Learners \\
\hline $\begin{array}{l}\text { Eliciting prior knowledge of ED before model lesson, } \\
\text { discussion contrasting inquiry, NOS, and PBL with ED } \\
\text { after model lesson }\end{array}$ & $\begin{array}{l}\text { Develop Teachers' Understandings of the Fundamentals and } \\
\text { Connections between Science, Engineering, and } \\
\text { Technology }\end{array}$ \\
\hline $\begin{array}{l}\text { Teachers worked in teams on model lessons, group debrief } \\
\text { discussions relating ED lessons to NOS ideas of } \\
\text { collaboration, why the problem is important to solve, etc. }\end{array}$ & Help Teachers Understand Engineering as a Social Practice \\
\hline
\end{tabular}

the data set was independently coded by one of the first three authors. When questions arose as to whether or not ED was present, the coder indicated this and these instances were discussed and agreed upon by the coding team. In instances in which the observation form did not contain enough information to make a determination of whether ED was present but a video existed, the video was observed and a determination as to the presence or absence of ED made. In instances in which no determination could be made from the observation form and no video was available, a conservative determination of no ED present was made.

Lessons which were determined to have ED were then coded for the content area in which the ED activity occurred (i.e. life science, physical science, earth/space/environmental science, general science) according to state Standards, and the features of ED present (i.e. problem identification, generate design solutions, create and improve models, and communicate findings).

Frequencies at each of the four time points were then analysed through inferential statistics. To compare the proportion of the teachers in treatment versus the control group who integrated ED into instruction, a chi-square test for independence with Yates Continuity Correction was used. The two variables were group (treatment or control) and incorporation of ED (yes or no). The Phi coefficient $\left(r_{\phi}\right)$, which ranges from 0 to 1 , was used as a measure of effect size with the two by two contingency tables.

Observation forms that indicated ED was incorporated on the observation day were flagged so these videos could be watched. (See below for a description of how videotaped classroom observations were analysed.)

\section{Classroom observations}

Observers visited each teacher's classroom once during each observation period to videotape their science instruction. Videotaped classroom observations in which ED was identified as present from the observation forms (see above) were watched and field notes recorded. These field notes were used to describe, in more detail, how teachers incorporated ED into instruction.

For each videotaped observation in the data set, field notes were read and the presence of the following, which were derived from the literature and inductively from the data, 
were coded: lesson topic, whether students were applying science content to solve a problem through ED or learning new science content through an ED task, and the components of ED observed (e.g. problem identification, generate design solutions, create and improve models, communicate findings). Themes and trends in the data were interpreted across these coded field notes. Exemplars of these themes and trends are included as vignettes in the results below.

\section{Results}

In this section we first present results of the relative frequency of ED integration for treatment and control teachers. Then, we present results of the analysis of content taught and ED components implemented. Finally, we present three vignettes that exemplify the trends observed in content and ED components addressed during ED tasks in treatment teachers' classrooms.

\section{Prevalence of integration}

Of the 219 treatment teachers, 121 (55.3\%) taught at least one lesson during an observation that integrated ED. Across the 4 observation windows, treatment teachers taught a total of 174 lessons that integrated ED. Three treatment teachers integrated multiple ED lessons into observation window 3. Of the 145 control teachers, 35 (24.1\%) taught at least one lesson that integrated ED. Forty-eight control lessons taught incorporated ED. Two control teachers integrated multiple ED lessons in observation window 1 and one control teacher integrated multiple ED lessons in observation window 4. Chi-square test for independence with Yates Continuity Correction indicated significantly more treatment teachers integrated ED lessons than control teachers, $\chi^{2}(1, n=401)=33.225, p<.001, r_{\phi}=$ 0.308 . The medium effect size $\left(r_{\phi}>0.243\right)$ combined with a statistically significant association represents a practically and statistically meaningful effect (Fan, 2001).

Results indicated between $17 \%$ and $30 \%$ of treatment teachers and between $7 \%$ and $11 \%$ of control teachers integrated ED into instruction during any given observation window (Table 3). Treatment teachers integrated ED significantly more frequently than control teachers across observation windows 2 through 4 . However, these effect sizes are small (Cohen, 1988); thus, it is possible they are due to statistical power and the statistically significant associations should be interpreted with caution.

\section{Content taught through ED}

Of the 174 ED lessons taught by treatment teachers, physical science content was most frequently addressed (62.3\%) followed by earth/space/environmental science topics

Table 3. Frequency of ED integration.

\begin{tabular}{lcccrc}
\hline Observation window & Treatment $(n=219)$ & Control $(n=145)$ & Chi-square (continuity correction) & Sign. & $r_{\varphi}$ \\
\hline 1 & $30(17.2 \%)$ & $11(7.6 \%)$ & 2.678 & .102 & 0.095 \\
2 & $49(22.4 \%)$ & $10(6.9 \%)$ & 14.270 & $<.001$ & 0.206 \\
3 & $41(18.7 \%)$ & $11(7.6 \%)$ & 7.948 & $\mathbf{0 0 5}$ & 0.156 \\
4 & $52(29.9 \%)$ & $16(11.0 \%)$ & 9.006 & .003 & 0.164 \\
\hline
\end{tabular}


(34.7\%), life science ideas (4.8\%), and general science content (e.g. process skills, experimental design) (1.2\%). Similar trends were observed for those lessons taught by control teachers. Of the 48 lessons incorporating ED taught by control teachers, most addressed physical science content (62.5\%), followed by earth/space/environmental science $(29.2 \%)$, life science content (6.2\%), general science content (2.1\%) (Table 4). For each content area, chi-square analysis indicated no significant difference in the number of lessons taught by treatment and control teachers (all $p$ 's $>.05$ ).

Qualitative analysis of the videotaped classroom observations suggested that lessons typically involved students applying science content to solve a problem through ED rather than students learning science content through an ED task (Table 5). Life science topics taught through ED were least prevalent in the data. While almost all of the physical and earth/space/environmental ED tasks resulted in physical prototypes or models for testing, life science-oriented ED tasks were often conceptual in nature (e.g. design a way to pollinate flowers without bees).

\section{Components of ED implemented}

Within the ED lessons teachers typically identified the problem (including the context, need, and specifications) for students. Students conducted research, completed designs, constructed, tested, and evaluated models. Brainstorming, revising, retesting, and communicating findings were less characteristic of ED lessons in the data set in the ED lessons. Students most often worked in small groups and rarely worked individually on ED tasks. Few ED tasks were whole-class such that each small group's prototype or design contributed to an overall class prototype or design. Data also suggested that many teachers incorporated ED tasks into PBL units.

Below, we provide three vignettes (one each that addresses physical, earth/space/ environmental, and life science content) that demonstrate the varied nature of ED integrated into instruction and how treatment teachers used ED tasks to support students' science content knowledge following their participation in the PD.

\section{Vignette 1 (physical science)}

This vignette, which occurred in a fifth grade class, exemplified how teachers incorporated ED to support students' application of physical science content. In the lessons leading up to the ED activity, students learned about the properties of sound through a series of investigations. The stated learning objective for the ED activity, which took place during one class period, was, 'Students will work through the engineer process to design and create a musical instrument from recycled materials and will need to demonstrate how it

Table 4. Content taught through ED.

\begin{tabular}{lcccc}
\hline & \multicolumn{4}{c}{ Content area addressed $(n, \%$ of lessons) } \\
\cline { 2 - 5 } Condition & Physical science & Earth/space science & Life science & General science \\
\hline Treatment $(n=174)$ & 104 & 58 & 8 & 2 \\
Control $(n=48)$ & $(62.3 \%)$ & $(34.7 \%)$ & $(4.8 \%)$ & $(1.2 \%)$ \\
& 30 & 14 & 3 & 1 \\
& $(62.5 \%)$ & $(29.2 \%)$ & $(6.3 \%)$ & $(2.1 \%)$ \\
\hline
\end{tabular}


Table 5. Topics addressed and ED tasks within content areas.

\begin{tabular}{|c|c|c|c|}
\hline Content area & Topics addressed & Representative ED tasks & Other characteristics \\
\hline Physical science & $\begin{array}{l}\text { Electricity, simple machines, } \\
\text { sound, and force, motion, } \\
\text { and energy }\end{array}$ & $\begin{array}{l}\text { Circuit building, instrument, bridge, } \\
\text { tower, submersible, roller coaster, } \\
\text { rocket }\end{array}$ & $\begin{array}{l}\text { Typically had physical model } \\
\text { or prototype (e.g. build a } \\
\text { circuit that can light a light }\end{array}$ \\
\hline $\begin{array}{l}\text { Earth/space/ } \\
\text { environmental } \\
\text { science }\end{array}$ & $\begin{array}{l}\text { Human impacts on the } \\
\text { environment, space, } \\
\text { erosion, watersheds, } \\
\text { oceans, weather }\end{array}$ & $\begin{array}{l}\text { Water filter, rover, watershed, ocean } \\
\text { floor model, ways to contain/clean } \\
\text { up oil spills, hurricane-proof } \\
\text { building, weather instrument }\end{array}$ & bulb) \\
\hline Life science & $\begin{array}{l}\text { Ecosystems, homeostasis, } \\
\text { and plants }\end{array}$ & Gardens, ecosystems, habitats & $\begin{array}{l}\text { Conceptual (e.g. design a } \\
\text { way to pollinate flowers } \\
\text { without bees) }\end{array}$ \\
\hline
\end{tabular}

works and have it produce sound with a variety of pitches' (E4-T428, Observation form 3). The teacher elaborated on this objective, noting:

This lesson serves as an application assessment of students creating a prototype of an instrument using real world materials (recycled materials collected as a class) and science equipment. This lesson provides the students with an understanding of how engineers and scientists work through a process to create a product or gain additional understanding of something known or unknown. (E4-T428, Observation form 3, italics added)

The teacher's learning objective included both science and engineering goals. She wanted students to understand the process engineers use to create something and demonstrate their understanding of a specific property of sound and pitch, by creating something that could produce varied pitches.

The lesson begins with the teacher giving directions for the activity, describing the specifications and constraints as well as the ED process the students will follow. She tells them that each group's final instrument has to be an original design (e.g. they cannot use a design they found off of the Internet, though they can use the Internet to do background research as they developed their design) and create sounds of varied pitches, which they will demonstrate to the class (specification). The teacher gives each group a specified amount of fake money to buy supplies and students have to use the recycled materials on hand (constraint). The teacher suggests that they not spend all of their money on the initial prototype materials in case something does not work and they had to purchase something else to fix it.

First, students work in pairs to create a design and develop a budget to purchase the items they need to construct their instrument. After their designs are approved by the teacher, groups are able to purchase materials and begin building their instruments using recycled materials, modifying their designs as needed. Students have time to test and retest their instruments during the building period. At the end of the activity, each group presents what they have built so far and explain how the instrument will work. (E4-T428, Observation 3)

The physical science ED activity described above clearly supported application of students' knowledge of the properties of sound in that all groups created instruments that produced sound. In a lesson subsequent to the one observed, students created an advertisement that showed the abilities of the instrument to encourage people to buy it. Thus, unlike most ED lessons in the data set, students engaged in the entire cycle of ED except problem identification. They generated design solutions, created and improved their instrument prototypes, and shared their findings with the class during this activity. Thus, this example represents the most complete ED cycle integration observed in teachers' classrooms following the PD. 


\section{Vignette 2 (earth/space/environmental science)}

This vignette, which occurred in a fourth grade class, exemplified how teachers incorporated ED to support students' understanding of earth science content. Prior to the ED activity, students learned about watersheds, habitats, niches, and water quality/pollution (E2-T201, Observation form 1).

To begin the lesson, which took place over three days, students discuss animals affected by water quality and how watersheds can be altered to assist in preventing water pollution. Then, she introduces the watershed ED activity: Students will work in groups to design and build a watershed model using the materials provided (constraints). She reminds the students that this is a competition among groups to see which watershed model has the least erosion and best prevents pollution (specification) and that each groups' watershed will be connected to a river table that represents the Chesapeake Bay. The goal is for each individual watershed model to prevent pollution (represented by Kool Aid) into the Chesapeake Bay (the river table).

Potential materials students have access to include paint trays to represent the area of a watershed, modeling clay, plastic sheaths (to represent impervious pavements), Easter grass, straws, floral tape, and Duplos (to represent buildings).

Students are divided into groups by the teacher and begin by thinking and planning their watershed model design before they get their paint tray watershed model and materials. The teacher walks among the groups as they are brainstorming their watershed models. Students spend about 20 minutes discussing watersheds with each other and how to make one. As students plan, the teacher tells them that tomorrow they will receive additional materials: sand, rocks and soil to add to their watershed models.

After planning, student groups begin building their watershed models as the teacher continues to circulate. Students work on building their models for 2 days and on the 3rd day they test their model by connecting it to the river table and adding Kool-aid water to determine the degree of erosion and pollution of their watershed relative to other groups. (E2T201, Observation 1)

This lesson represents the typical characteristics of ED lessons observed in the data set. Similar to the physical science ED activity, students applied what they previously learned about watersheds in their design. However, unlike the physical science ED activity, there is no evidence that students conducted background research to inform the design of their models. Rather, they relied solely on their previous knowledge of watersheds, erosion, and pollution. In addition there is no evidence that they had opportunities to retest or redesign their watershed model to improve it after their initial test. While students shared their designs during the testing phase, it did not appear that they shared their design rationales or thinking with the class. These omissions of research, evaluating and redesigning, and communicating findings within the ED process were typical of the majority of lessons in the data set.

\section{Vignette 3 (life science)}

This ED activity occurred in a fourth grade class over a week during a unit on habitats. It exemplified how teachers incorporated ED to support students' understanding of life science content. Unlike the other examples of ED, most of the life science ED activities 
resulted in a conceptual model of the product for evaluation rather than a working prototype. The objective of the activity was that students would learn about the habitats of a number of animals through their background research and discussion in putting all of the habitats into the design of a class zoo (E4-T410, Observation form 2).

In this ED activity, students began by working in small groups to select and conduct Internet research on an animal of their choice and its habitat and conceptualise an 'artificial' habitat for their animal in which it would be able to 'adapt and thrive' in a temperate climate (constraint). Students also researched how existing zoos create habitats for this animal. They used Prezi software to present information about their animal and its needs in terms of a habitat to the class. As each group presented, the class discussed each of the habitats and how they might be improved as well as where they might be placed in the larger zoological reserve. Then, the habitats were put together to create a zoological reserve for all the animals based on the governor's requirements (specification). On the observed day, in which students were beginning to put together their individual habitats into the zoo design:

The teacher lays a big paper down on the floor and each group puts their habitat design on the paper to plan the broader zoo. Students argue about the placement of habitats and the teacher facilitates a more directed discussion that guides them to consider grouping the animals in areas based on similar habitats.

Students divide into groups based on habitat similarities and continue planning their habitats, modifying the original habitats the individual groups proposed to meet the needs of their animal groups. They cut out and draw different objects to place on the paper, essentially creating a blueprint for the zoo.

At the end of this day, the students move into a discourse circle and the teacher facilitates a discussion of the progress, challenges, and plans for next steps in designing the zoo. (E4T410, Observation 2)

Subsequent days included students looking at their proposed zoo design as an entire class, getting feedback from an area zoo employee on the design, and discussing potential changes and rationales for changes to the zoo design. Finally, students had to develop a marketing strategy to attract customers and worked together to discuss the unique characteristics of the zoo that would draw visitors (E4-T410, Observation form 2).

This ED task represents one of the few in the data set in which students worked in small groups on an individual component of the overarching task and then put their component into a class-wide model. It also describes one of the few ED activities observed in which developing science content knowledge (e.g. animal habitats) was embedded into the design task rather than the design task being an application of students' science content knowledge.

Similar to the physical science vignette, in this ED task, students were involved in the entire cycle of ED except for problem identification. However, unlike the physical science instrument ED task, in which students tested their model, evaluation, and redesign of the individual habitats and overall zoo design was through whole-class discussion and peer and expert feedback.

\section{Discussion and implications}

Our results suggest that the PD, which was aligned with Cunningham and Carlsen's (2014) guidelines for ED PD, was effective in supporting upper elementary teachers' integration 
of ED into classroom science instruction. Significantly more treatment than control teachers incorporated ED into their instruction overall and during three of the four observation points. The frequency with which physical, earth/space/environmental, and life science content was addressed in ED tasks was similar for treatment and control teachers. Typical ED lessons observed emphasised students' application of science content to solve a teacher-generated problem and design and testing of a physical prototype or model. Less characteristic of the ED lessons in the data set were opportunities for students to re-design and retest models and communicate their findings.

\section{Prevalence of ED}

While just over half of treatment teachers were observed implementing ED into their science instruction, ED instruction was not the primary focus of the PD and it is encouraging that these teachers were able to apply what they learned during the four hours of targeted instruction on ED into their science instruction. Given that it may take teachers 3 to 6 years before teachers are comfortable engaging in engineering practices with their students' (Cunningham \& Carlsen, 2014, p. 209) the fact that significantly more treatment than control teachers in the present study implemented ED is promising for the immediate effectiveness of ED PD. We hypothesise that if teachers received more instruction on ED in PD aligned with the Cunningham and Carlsen (2014) guidelines or if ED was the primary goal of the $\mathrm{PD}$, the number of teachers who implemented $\mathrm{ED}$ into their science instruction would be greater. This hypothesis should be tested in the future through RCTs using the Cunningham and Carlsen (2014) PD guidelines.

Although more treatment than control teachers integrated ED, the non-significant difference in ED between treatment and control teachers during the first observation window merits further exploration. It is possible the order of science curriculum led to these results. Many elementary teachers spend substantial time in the beginning of the year setting up routines and expectations for their students before addressing specific science content. Often, scientific skills (e.g. observing, inferring, classifying, measuring, asking questions) is the first topic addressed in science instruction, and it is possible this curricular focus precluded teachers from engaging their students in ED tasks during the first observation window. It is also possible teachers feel students are not prepared to engage in ED at the outset of the academic year. Explanations for the observed pattern should be investigated to determine how to support sustained ED engagement that begins early in the academic year.

Our analysis indicated that most teachers transferred what they learned during the PD to meet their individual grade level and content needs, rather than implementing ED lessons identical to those modelled during the summer PD. Previous research suggests that teachers need a certain degree of ownership and flexibility when developing and implementing reform-based curriculum such as ED (Trumbull, Bonney, \& GrudensSchuck, 2005). Curriculum materials designed for broad use do not necessarily include the scaffolds certain teachers and students need and teachers may not know how to modify the provided materials to meet their needs (Drake, Land, \& Tyminski, 2014). Given the limitations of prepared ED curricula cited in the literature related to curricular needs (e.g. Katehi et al., 2009), it is encouraging that our teachers were able to apply what they learned to develop their own ED activities. The results of this study supports the 
efficacy of utilising Cunningham and Carlsen's (2014) PD model to support teachers in integrating $\mathrm{ED}$ into science instruction and extends previous research that primarily looked at PD to facilitate teachers' integration of prepared ED curricula (e.g. Lachapelle \& Cunningham, 2014).

\section{Content addressed through ED tasks}

Previous researchers have suggested a variety of learning objectives can be met by including ED tasks into science instruction (e.g. Ainley et al., 2006; Kanter, 2010; Krajcik et al., 2008). Results of the present study support these previous findings; teachers' stated learning objectives were most often for students to apply science content they learned prior to the ED challenge. Rarely was learning new science content simultaneous or embedded within the ED task.

Katehi et al. (2009) indicate that most prepared elementary engineering curricula focuses on physical science content. Despite the fact that they were generating their own ED tasks to meet curricular and state standards for their grade levels, teachers in the present study also focused ED tasks most frequently on physical science content. One reason for this observed prevalence is that across the fourth through sixth grade few science standards in the state studied, address life processes and living systems. There is greater emphasis on physical and earth/space science concepts in the state standards. Thus, it is possible the greater emphasis on physical and earth/space science concepts in ED tasks observed in the present study is a result of the greater emphasis on these concepts in this state's standards. However, Roehrig, Moore, Wang, and Park (2012) found that middle and high school life science teachers found it difficult to incorporate engineering into their instruction due to the common belief that engineering products needed to be physical prototypes. Our results lend further support to the idea that it may be especially important for PD to model ED within life science and to include a range of products, including design briefs, to support a broad understanding of ED and support integration across science disciplines.

\section{Components of the ED cycle}

Data indicated that teachers gave students the overarching problem to solve along with constraints and specifications for the ED task, as exemplified in the three vignettes presented above. It is possible the teacher did not provide greater choice to students in order to ensure certain content learning objectives were met. Defining problems is an important engineering practice and students should have opportunities to engage in this (e.g. NRC, 2012). If teachers are not able or willing to have students define problems to solve given curricular constraints or instructional goals for an ED task, it is important that they find other ways to include problem identification in their curriculum to allow students to practice this skill. In some ways, our findings are analogous to those identified in regards to teachers' inquiry-based instruction where students seldom have the opportunity to develop their own research questions (Crawford, 2014). It may be valuable to conceptualise levels of ED instruction similar to models of inquiry instruction (e.g. Banchi \& Bell, 2008; Bell, Smetana, \& Binns, 2005; Herron, 1971). For example, when ED instruction is most student-centred (Level 4), students have the opportunity to 
develop and define a problem, determine how to solve the problem, establish a way to test the solution, and evaluate the extent the solution did or would meet the design specifications. On the other end of the spectrum (Level 1), ED instruction that is teacher-centred would only allow students to evaluate the extent the solution did or would meet the design specifications (Table 6).

In contrast to concerns in previous studies that many elementary teachers find it challenging to allow students to engage in open-ended ED tasks with multiple solutions (e.g. Cunningham \& Carlsen, 2014; Katehi et al., 2009), teachers in the present investigation seemed to support students in engaging in ED tasks that had a variety of potential solutions through a facilitative role. These lessons reflected Level 3 ED in our proposed scaffolded model. It is possible the focus on PBL during the summer institute, which included the opportunity for teachers to practice engaging students in open-ended tasks and then debrief these with other teachers and facilitators, supported teachers' comfort in engaging students in ED tasks.

Some participants who engaged students in ED tasks also missed opportunities for students to redesign and retest their models or communicate their findings. We hypothesise that time constraints for science instruction in elementary classrooms may have been one reason teachers left out the opportunities for students to iterate their designs. However, like problem identification, the literature suggests these are important ED practices that students should have opportunities to engage in (e.g. Eide, Jenison, Mashaw, \& Northrup, 2001; ITEA, 2000; Katehi et al., 2009). While the modelled ED lessons during the PD provided teachers the opportunity to complete an entire design cycle, there is a need to explicitly emphasise the importance of these practices and how they develop students' understandings of both science content and the nature of engineering. Additionally, discussing practical aspects and ways to overcome challenges to implementation may also improve teachers' implementation of entire ED cycles during science instruction.

\section{Limitations and future research}

The results of the present investigation indicate the structure of the PD was efficacious in getting teachers to include ED in their science instruction. A limitation of the study is that we do not know what specific components of the PD were most important in producing the change in teachers' practices, nor do we know how the ED PD interacted with the broader goals of the PD to support teachers' integration of ED into their instruction. Future research should include interviews of teachers to ascertain the components of the PD they perceived as most important in facilitating changes in their ED integration. It is also important to understand the ED practices teachers perceived as most difficult

Table 6. Design components completed by students in teacher directed (Level 1) versus student directed (Level 4) ED.

\begin{tabular}{lcccc}
\hline & Identify/define problem & Plan/build a solution & Design a way to test solution & Evaluate the solution \\
\hline Level 1 & $\mathrm{X}$ & $\mathrm{X}$ & $\mathrm{X}$ & $\mathrm{X}$ \\
Level 2 & $\mathrm{X}$ & $\mathrm{X}$ & & \\
Level 3 & $\mathrm{X}$ & & & \\
Level 4 & & & & \\
\hline
\end{tabular}


to implement into their science instruction and why they perceived the difficulties existed. Future research in states that emphasise different science topics in grades 4-6 should examine the content teachers choose to teach through ED to test the hypothesis that life science content was not included to a greater extent by teachers in the present study due to relative emphasis on the standards. Finally, it will be important to show in future research that the ED tasks developed by teachers were, in fact, useful in supporting students' science content understandings, understandings of ED practices, and understandings of the differences and intersections of science and engineering, as these are important goals espoused in K-12 science education (NRC, 2012).

Despite the limitations of the present study, the results of this RCT support the efficacy of using the Cunningham and Carlsen (2014) guidelines to inform the development of ED PD. PD aligned with these guidelines clearly has the potential to influence in-service elementary teachers' implementation of ED in science instruction. Ultimately, the results of the present study should be of interest to those involved in the development of ED PD for in-service elementary teachers. Furthermore, our conceptualisation of levels of ED provide an opportunity to view ED instruction along a continuum that supports teachers and student growth in key components of engineering.

\section{Disclosure statement}

No potential conflict of interest was reported by the authors.

\section{Funding}

This work was supported by U.S. Department of Education (Investing in Innovation, grant number U396B100039).

\section{ORCID}

Jennifer L. Maeng (iD http://orcid.org/0000-0003-4955-4023

\section{References}

Ainley, J., Pratt, D., \& Hansen, A. (2006). Connecting engagement and focus in pedagogic task design. British Educational Research Journal, 32(1), 23-38.

Apedoe, X. S., Reynolds, B., Ellefson, M. R., \& Schunn, C. D. (2008). Bringing engineering design into high school science classrooms: The heating/cooling unit. Journal of Science Education and Technology, 17(5), 454-465.

Banchi, H., \& Bell, R. L. (2008). The many levels of inquiry. Science and Children, 46(2), 26-29.

Barnett, M. (2005). Engaging inner city students in learning through designing remote operated vehicles. Journal of Science Education and Technology, 14, 87-100.

Bell, R. L., Konold, T., Maeng, J. L., \& Heinecke, W. (2014). VISTA research and evaluation annual report. Charlottesville, VA: Curry School of Education, University of Virginia.

Bell, R. L., Smetana, L. K., \& Binns, I. (2005). Simplifying inquiry. The Science Teacher, 72(7), 30-34.

Birman, B. S., Desimone, L., Porter, A. C., \& Garet, M. S. (2000). Designing professional development that works. Educational Leadership, 57(8), 28-33.

Blumenfeld, P. C., Kempler, T. M., Krajcik, J. S., \& Blumenfeld, P. (2006). Motivation and cognitive engagement in learning environments. In R. K. Sawyer (Ed.), The Cambridge handbook of the learning sciences (pp. 475-488). New York, NY: Cambridge University Press. 
Borko, H. (2004). Professional development and teacher learning: Mapping the terrain. Educational Researcher, 33, 3-15.

Brophy, S., Klein, S., Portsmore, M., \& Rogers, C. (2008). Advancing engineering education in P-12 classrooms. Journal of Engineering Education, 97, 369-387.

Chiu, J. L., \& Linn, M. C. (2011). Knowledge integration and wise engineering. Journal of PreCollege Engineering Research, 1, 1-14.

Cohen, J. (1988). Statistical power analysis for the behavioral sciences (2nd ed.). Hillsdale, NJ: Lawrence Earlbaum.

Crawford, B. A. (2014). From inquiry to scientific practices in the science classroom. In Norman G. Lederman \& Sandra K. Abell (Eds.), Handbook of research on science education. Abingdon: Routledge. doi:10.4324/9780203097267.ch26

Creswell, J. W., \& Plano Clark, V. L. (2011). Designing and conducting mixed methods research (2nd ed.). Thousand Oaks, CA: Sage.

Cunningham, C. M. (2009). Engineering is elementary. The Bridge (National Academy of Engineering), 30(3), 11-17.

Cunningham, C. M., \& Carlsen, W. S. (2014). Teaching engineering practices. Journal of Science Teacher Education, 25, 197-210.

Dare, E. A., Ellis, J. A., \& Roehrig, G. H. (2014). Driven by beliefs: Understanding challenges physical science teachers face when integrating engineering and physics. Journal of Pre-College Engineering Education, 4(2), 47-61.

Desimone, L. M. (2009). Improving impact studies of teachers' professional development: Toward better conceptualizations and measures. Educational Researcher, 38, 181-199.

Drake, C., Land, T. J., \& Tyminski, A. M. (2014). Using educative curriculum materials to support the development of prospective teachers' knowledge. Educational Researcher, 43, 154-162.

Dym, C. L., Agogino, A. M., Eris, O., Frey, D. D., \& Leifer, L. J. (2005). Engineering design thinking, teaching, and learning. Journal of Engineering Education, 94, 103-120. doi:10.1002/j.2168-9830. 2005.tb00832.x

Eide, A. R., Jenison, R. D., Mashaw, L. H., \& Northrup, L. (2001). Engineering fundamentals and problem solving (4th ed.). Boston, MA: McGraw-Hill.

Fan, X. (2001). Statistical significance and effect size in education research: Two sides of a coin. Journal of Educational Research, 94, 275-282.

Fortus, D., Krajcik, J., Dershimer, R. C., Marx, R. W., \& Mamlok-Naaman, R. (2005). Design-based science and real-world problem solving. International Journal of Science Education, 27, 855-879. doi:10.1080/09500690500038165

Grierson, A. L., \& Woloshyn, V. E. (2013). Walking the talk: Supporting teachers' growth with differentiated professional learning. Professional Development in Education, 39, 401-419.

Herron, M. D. (1971). The nature of scientific inquiry. School Review, 79(2), 171-212.

Hmelo, C. E., Holton, D. L., \& Kolodner, J. L. (2000). Designing to learn about complex systems. Journal of the Learning Sciences, 9(3), 247-298.

International Technology Education Association (ITEA). (2000). Standards for technological literacy: Content for the study of technology. Reston, VA: ITEEA.

Johnson, C. C., Kahle, J. B., \& Fargo, J. D. (2007). Effective teaching results in increased science achievement for all students. Science Education, 91, 371-383. doi:10.1002/sce.20195

Kanter, D. E. (2010). Doing the project and learning the content: Designing project-based science curricula for meaningful understanding. Science Education, 94, 525-551.

Katehi, L., Pearson, G., \& Feder, M. (Eds.). (2009). Engineering in K-12 education: Understanding the status and improving the prospects. Washington, DC: National Academies Press.

Klahr, D., Triona, L. M., \& Williams, C. (2007). Hands on what? The relative effectiveness of physical versus virtual materials in an engineering design project by middle school children. Journal of Research in Science Teaching, 44, 183-203.

Kolodner, J. L. (2006). Case-based reasoning. In R. K. Sawyer (Ed.), The Cambridge handbook of the learning sciences (pp. 225-242). Cambridge: Cambridge University Press. 
Kolodner, J. L., Camp, P. J., Crismond, D., Fasse, B., \& Gracy, J. (2003). Problem-based learning meets case-based reasoning in the middle-school classroom: Putting leaning by design into practice. The Journal of the Learning Sciences, 12, 495-547.

Krajcik, J., McNeill, K. L., \& Reiser, B. J. (2008). Learning-goals-driven design model: Developing curriculum materials that align with national standards and incorporate project-based pedagogy. Science Education, 92, 1-32. doi:10.1002/sce.20240

Lachapelle, C. P., \& Cunningham, C. M. (2014). Engineering in elementary schools. In J. Strobel, S. Purzer, \& M. Cardella (Eds.), Engineering in pre-college settings: Synthesizing research, policy, and practices (pp. 61-88). Lafayette, IN: Purdue University.

Levy, S. T. (2013). Young children's learning of water physics by constructing working systems. International Journal of Technology and Design Education, 23, 537-566.

Loucks-Horsley, S., \& Matsumoto, C. (1999). Research on professional development for teachers of mathematics and science: The state of the scene. School Science and Mathematics, 99, 258-271.

Loucks-Horsley, S., Stiles, K. E., Mundry, S., Love, N., \& Hewson, P. (2010). Designing professional development for teachers of mathematics and science (3rd ed.). Thousand Oaks, CA: Corwin Press.

Luft, J. A., Firestone, J. B., Wong, S. S., Ortega, I., Adams, K., \& Bang, E. (2011). Beginning secondary science teacher induction: A two-year mixed methods study. Journal of Research in Science Teaching, 48, 1199-1224.

Mannarino, A., Logerwell, M. G., Reid, V. B., \& Edmondson, E. W. (2012). Refining inquiry-based science instruction through professional development using the VISTA Model. A paper for the annual meeting of the National Association of Research in Science Teaching, Indianapolis, IN.

National Research Council. (2012). The framework for K-12 science education. Washington, DC: National Academy Press.

National Science Board. (2003). The science and engineering workforce realizing America's potential. The National Science Foundation, NSB 03-69.

The Partnership for 21st Century Skills. (2010). Framework for 21st century learning. Retrieved from http://www.p21.org/

Roehrig, G. H., Moore, T. J., Wang, H.-H., \& Park, M. S. (2012). Is adding the E enough? Investigating the impact of K-12 engineering standards on the implementation of STEM integration. School Science and Mathematics, 112, 31-44. doi:10.1111/j.1949-8594.2011.00112.x

Supovitz, J. A., Mayer, D. P., \& Kahle, J. B. (2000). Promoting inquiry-based instructional practice: The longitudinal impact of professional development in the context of systemic reform. Educational Policy, 14, 331-356. doi:10.1177/0895904800014003001

Trumbull, D. J., Bonney, R., \& Grudens-Schuck, N. (2005). Developing materials to promote inquiry: Lessons learned. Science Education, 89(6), 879-900. 